\title{
ANN Based Flux and Torque Estimator for Vector Controlled Induction Drive with Dynamic Loading
}

\author{
D. D. Neema, R. N. Patel, Member, IEEE and A. S. Thoke, Member, IEEE
}

\begin{abstract}
Vector control of induction motor drives is very useful technique to obtain high performance speed response. Implementation of vector control requires the knowledge of instantaneous magnitude and position of rotor flux and load behavior in the shaft for correct dimensioning of an induction motor. This paper demonstrates estimation of feedback signals in a three phase induction motor derive under dynamic load conditions using Artificial Neural Network (ANN). A instantaneous magnitude and position of rotor flux and load torque estimator, in the form of a two stage neural network is presented. The neural network is able to accurately estimate these parameters of an induction motor. The observations indicate that ANN based flux and load torque estimation may be a feasible alternative to other rotor flux and load torque estimation methods like programmable DSP kit. The comparative performance of both has been presented in this work with the help of a practical three-phase induction motor drive.
\end{abstract}

Index Terms-Back propagation, DSP, FOC, Induction drive, Neural network, Vector control.

\section{INTRODUCTION}

In order to control an induction motor requiring high dynamic performance, an accurate knowledge of the instantaneous magnitude and position of rotor flux and load torque is necessary because these directly affect the mechanical power developed. Application of a motor depends upon the load behavior of the motor; therefore accurate estimation of these parameters is a difficult task for a drive under running condition.

Both direct Field Oriented Control (FOC), and indirect FOC, has been successfully established in theory and practice. In both control strategies the stator current components, responsible for the flux and torque production, is decoupled. This achieves independent control of torque and flux. Right from its introduction in the early 70's, the direct FOC scheme has been regarded as less practical [1]-[4], because sensors are needed to obtain information about the machine variables. The sensors include the search coils, coil taps, or Hall Effect sensors. Sensors often impose limitations on the machine's operating range (particularly at the low speed end) and also

Manuscript received December 16, 2008. This work was supported in part by AICTE, New Delhi (INDIA) through the 'Career Award for Young Teachers' scheme to Dr. R. N. Patel.

D. D. Neema is with the dept. of Electrical Engineering, RCET, Bhilai (C.G.), India,

R. N. Patel is with the dept. of Electrical Engineering, SSCET, Bhilai (C.G.), India, (Corresponding Author: Phone: +91-9827494379) India

A. S. Thoke is with the dept. of Electrical Engineering, NIT Raipur (C.G.), increase the overall cost of the machine. However, with the introduction of indirect FOC the hardware requirements are much simpler, resulting in better overall performance. In order for such a scheme to work, the accurate estimation of instantaneous magnitude and position of rotor flux and load torque is vital. There are a few schemes available today, most of which are based on adaptive control [5]-[8], whereas others use digital signal processing (DSP) for their estimator implementation [9]-[14]. In this paper an artificial neural network is described, as used for the estimation of the instantaneous magnitude and position of rotor flux and load torque for several operating points during line-start operation of an induction motor. The design of a two hidden layer neural networks is discussed in this work. The learning requirements of the design are evaluated by developing the back propagation learning technique for the instantaneous magnitude and position of rotor flux and load torque estimator.In balanced three-phase systems, the two axis (d-axis and q-axis) model is used for dynamic modeling of an induction motor [15]. In implementation of vector control technique, also known as FOC shown in Fig.1, the three phase induction motor works as a two phase motor in which $\mathrm{i}_{\mathrm{ds}}$ is in the direction of flux $\psi_{\mathrm{r}}$ and the $\mathrm{i}_{\mathrm{qs}}$ perpendicular to it. This alignment in stationary $\mathrm{d}-\mathrm{q}$ model (regarded as $\mathrm{d}^{\mathrm{s}}-\mathrm{q}^{\mathrm{s}}$ ), an induction motor can be expressed in either a stationary or a rotating reference frame. In stationary reference frame, the reference $d$ and $q$ axes are fixed on the stator. In synchronous rotating $\left(\mathrm{d}^{\mathrm{e}}-\mathrm{q}^{\mathrm{e}}\right)$ frame, rotating at synchronous speed with respect to stationary frame $\left(\mathrm{d}^{\mathrm{s}}-\mathrm{q}^{\mathrm{s}}\right)$ at any instant, the angular position of the $\mathrm{d}^{\mathrm{e}}$-axis with respect to the $\mathrm{d}^{\mathrm{s}}$-axis is $\theta_{\mathrm{e}}$, where $\theta_{\mathrm{e}}=\mathrm{w}_{\mathrm{e}} \mathrm{t}$.

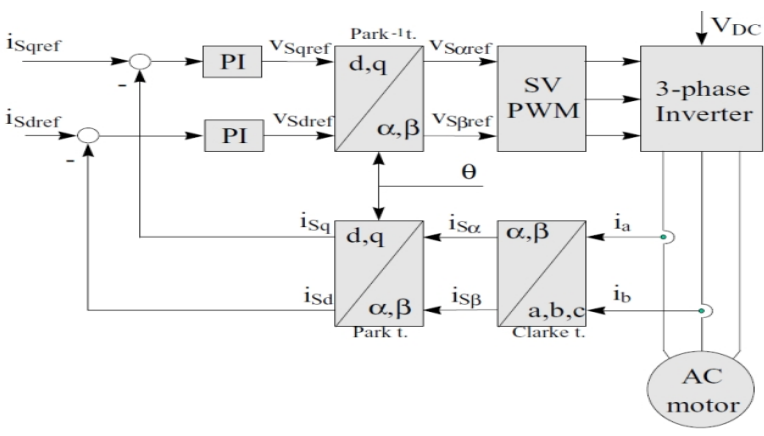

Fig. 1. FOC structure of three phase induction drive

In Fig. 1, the two phase currents feed the Clarke transformation module. These projection outputs are indicated $i_{S \alpha}$ and $i_{S \beta}$. These two components of the current provide the input of the Park transformation that gives the current in the $d-q$ rotating reference frame. The $i_{S d}$ and $i_{S q}$ 
components are compared to the references $i_{\text {Sdref }}$ (the flux reference) and $\mathrm{i}_{\text {Sqref }}$ (the torque reference). The torque command $i_{\text {Sqref }}$ corresponds to the output of the speed regulator. The flux command $i_{\text {Sdref }}$ is the output of the field weakening function (not shown in figure) that indicates the right rotor flux command for every speed reference. The current regulator outputs are $\mathrm{v}_{\text {Sdref }}$ and $\mathrm{v}_{\text {Sqref }}$; they are applied to the inverse Park transformation. The outputs of this projection are $\mathrm{v}_{\mathrm{S} \alpha \mathrm{ref}}$ and $\mathrm{v}_{\mathrm{S} \beta \mathrm{ref}}$, the components of the stator vector voltage in the $\alpha$ - $\beta$ orthogonal reference frame. These are the input of the Space Vector PWM. The outputs of this block are the signals that drive the inverter. Note that both Park and inverse Park transformations require the rotor to be in flux position which is given by the current model block.

It is necessary to estimate the rotor flux components $\psi_{\mathrm{dr}}$ and $\psi_{\mathrm{qr}}$ so that the rotor flux and the unit vector $\left(\operatorname{Sin} \theta_{\mathrm{e}}, \operatorname{Cos} \theta_{\mathrm{e}}\right)$ can be calculated. The rotor flux and unit vector are estimated by either voltage model equations or current model equations. In voltage model the machine terminal voltage and currents are sensed and the fluxes are computed from the stationary frame $\left(d_{s}-q_{s}\right)$. The dynamic model of a three phase induction motor gives the machine equations in the following forms (the notations used carry their conventional meanings).

$$
\begin{aligned}
\mathrm{v}_{\mathrm{ds}} & =2 / 3 \mathrm{v}_{\mathrm{a}}-1 / 3 \mathrm{v}_{\mathrm{b}}-1 / 3 \mathrm{v}_{\mathrm{c}} \\
\mathrm{v}_{\mathrm{qs}} & =-\sqrt{3} / 2\left(\mathrm{v}_{\mathrm{b}}+\mathrm{v}_{\mathrm{c}}\right) \\
\mathrm{i}_{\mathrm{ds}} & =2 / 3 \mathrm{i}_{\mathrm{a}}-1 / 3 \mathrm{i}_{\mathrm{b}}-1 / 3 \mathrm{i}_{\mathrm{c}} \\
\mathrm{i}_{\mathrm{qs}} & =-\sqrt{3} / 2\left(\mathrm{i}_{\mathrm{b}}+\mathrm{i}_{\mathrm{c}}\right) \\
\Psi_{\mathrm{ds}} & =\int\left(\mathrm{v}_{\mathrm{ds}}-\mathrm{R}_{\mathrm{s}} \mathrm{i}_{\mathrm{ds}}\right) \mathrm{dt} \\
\Psi_{\mathrm{qs}} & =\int\left(\mathrm{v}_{\mathrm{qs}}-\mathrm{R}_{\mathrm{s}} \mathrm{i}_{\mathrm{qs}}\right) \mathrm{dt} \\
\Psi_{\mathrm{qm}} & =\Psi_{\mathrm{qs}}-\mathrm{L}_{\mathrm{s}} \mathrm{i}_{\mathrm{qs}} \\
\Psi_{\mathrm{dm}} & =\Psi_{\mathrm{ds}}-\mathrm{L}_{\mathrm{s}} \mathrm{i}_{\mathrm{ds}} \\
\Psi_{\mathrm{qr}} & =\left(\mathrm{L}_{\mathrm{r}} / \mathrm{L}_{\mathrm{m}}\right) \Psi_{\mathrm{qm}}-\mathrm{L}_{\mathrm{r}} \mathrm{i}_{\mathrm{qs}} \\
\Psi_{\mathrm{dr}} & =\left(\mathrm{L}_{\mathrm{r}} / \mathrm{L}_{\mathrm{m}}\right) \Psi_{\mathrm{dm}}-\mathrm{L}_{\mathrm{r}} \mathrm{i}_{\mathrm{qs}} \\
\Psi_{\mathrm{r}} & =\sqrt{ }\left[\left(\Psi_{\mathrm{qr}}\right)^{2}+\left(\Psi_{\mathrm{dr}}\right)^{2}\right] \\
\operatorname{Cos} \theta & =\left(\Psi_{\mathrm{dr}} / \Psi_{\mathrm{r}}\right) \\
\operatorname{Sin} \theta & =\left(\Psi_{\mathrm{qr}} / \Psi_{\mathrm{r}}\right) \\
\mathrm{T}_{\mathrm{e}} & =(3 \mathrm{P} / 4)\left(\Psi_{\mathrm{ds}} \mathrm{i}_{\mathrm{qs}}-\Psi_{\mathrm{qs}} \mathrm{i}_{\mathrm{ds}}\right)
\end{aligned}
$$

As the voltage model flux estimation is better at higher speed ranges, whereas the current model estimation can be made at any speed, a hybrid model is used in some works [14]. However, it is important to note that the estimation accuracy is affected by variation of machine parameters, which are difficult to obtain correctly under dynamic load conditions. Both voltage and current models require motor parameters such as stator resistances, and inductances or rotor resistance as well as inductance simultaneously. Accurate knowledge and representation of these parameters is essential to achieve the highest possible efficiency from the control structure. It is also observed that resistance has a wide variation primarily due to temperature variation during operation and to a smaller degree due to stator frequency variations. In the proposed scheme, the parameter sensitivity would not greatly plague the accuracy of the measurement and calculation of flux, torque and field angle. A partial operating frequency dependent hybrid flux estimator for stator resistance tuning [16] has problems of convergence and slow response, thereby necessitating the use of intelligent control technique such as Neural Networks and Fuzzy Logic.

\section{ARTIFICIAL NEURAL NETWORKS IN VECTOR CONTROL INDUCTION MOTOR}

Most control techniques of squirrel cage Induction Motor (IM) require speed feedback signal from the shaft encoder and these devices have various disadvantage and are undesirable in many applications [17], [18]. In order to control an IM requiring high dynamic performance, an accurate knowledge of the load torque is necessary. Vector controlled induction motor drive operates like a separately excited dc motor using the $d-q$ axis dynamic equations of the induction motor [1]. The instantaneous magnitude and position of rotor flux and load torque is estimated using stator current and voltage measurement in various operating conditions of the induction motor. Various methods in control system theory have been applied to improve robustness of a motor control system.

Making a motion control system intelligent requires soft computational methods such as fuzzy logic and ANN [19]-[21]. This paper presents an application of ANN to estimate the instantaneous magnitude and position of rotor flux and load torque. The ANN is an interconnection of many nonlinear computational neuron or perceptions capable of high speed nonlinear computation due to its parallel structure [21]. The input of each individual neuron sums $\mathrm{N}$ weighted inputs and passes the result through an activation function, to give an output. Three common types of activation function are hard limit, threshold and sigmoid. The input weights of each neuron are adjusted during training to improve performance. Thus, ANN uses a self learning process. The ANN computing differs from traditional computing; as neural nets generate their own rules by learning from examples. In situations where traditional computing systems are rendered useless by even a small amount of damage to memory, neural nets are fault tolerant.

\section{PROPOSED ANN STRUCTURE}

Back propagation (BP) neural network structure is used for estimation of vector controlled induction motor parameters such as torque, speed, flux magnitude and position, because in BP network each unit receives input from preceding layer. The significance of this is that the information going into the hidden layer units reorder into an internal representation and outputs are generated by this internal representation rather than by inputs. The input signals are then converted by the ANN according to the connection weights. In learning process, connection weights update in a direction to minimize error between desired outputs and ANN outputs. These errors are then back-propagated.

The instantaneous magnitude and position of rotor flux and load torque estimation using single ANN structure has been tried out in most of the previous works [17], [18]. This paper proposes two ANN structure, one ANN structure estimates stator d-axis and q-axis flux using (5) and (6), whereas second ANN structure estimates the instantaneous magnitude of rotor q-axis flux, d-axis flux, rotor flux, rotor position and load torque using equations (9), (10), (11), (13), and (14) respectively. These dynamic equations are programmed into DSP 2407 kit and its performance is compared with that of proposed ANN estimator. The use of Artificial Neural 
Network (ANN) has the following advantages over the traditional methods:

1) The ANN after getting trained is reduced to a matrix weight data; the matrix solving requires lower processing time and power compared to equation solving.

2) The machine parameters are implicit in the network weights and thus do not require explicit knowledge of the exact values of the parameters which are difficult to obtain.

3) ANN has self-organizing capability, which gives robustness and fault tolerance ability under dynamic system conditions.

The block diagram of proposed ANN structure is shown in Fig. 2. The selection of hidden layer neurons normally requires several stage of iteration because there is no unique way to determine the optimum number of hidden layer neurons. If the number of neurons is small, the error of estimation will be high; whereas if the number of neurons is too large, the network will tend to memorize rather than learn. Various structures of the neural networks with various activation functions and different numbers of the neurons in the hidden layer were analyzed and the optimum architecture was decided based on the observations.

The first ANN Structure consist 4 layers (4-16-32-2) and uses 'tansig' and 'purelin' as activation functions, whereas Levenberg-Marquardt algorithm is used for training. The maximum number of iterations is 120 and the mean square error is 0.001 at learning rate of 0.04 to estimate stator d-axis and q-axis flux. The Second ANN structure also consist 4 layers (4-8-16-3) using 'tansig' and 'purelin' as activation functions and Levenberg-Marquardt algorithm is used for training; the maximum iteration is taken as 300 and target mean square error is 0.001 at learning rate of 0.04 to estimate the instantaneous magnitude and position of rotor flux and load torque. The input and target data for training are generated by using TMSLF 2407 DSP kit with the help of intelligent power module.

\section{RESUlTS AND DISCUSSIONS}

In this paper, application of ANN for the estimation of the instantaneous magnitude and position of rotor flux and load torque is suggested for a vector control induction motor drive. The various layers of BP ANN structure have been trained with help of Neural Network Toolbox of Matlab-Simulink [22]. The real system data in the form of three-phase voltage and current were obtained for a $1 \mathrm{hp}, 50 \mathrm{~Hz}, 3$-phase squirrel cage induction motor drive and processed with the help of the

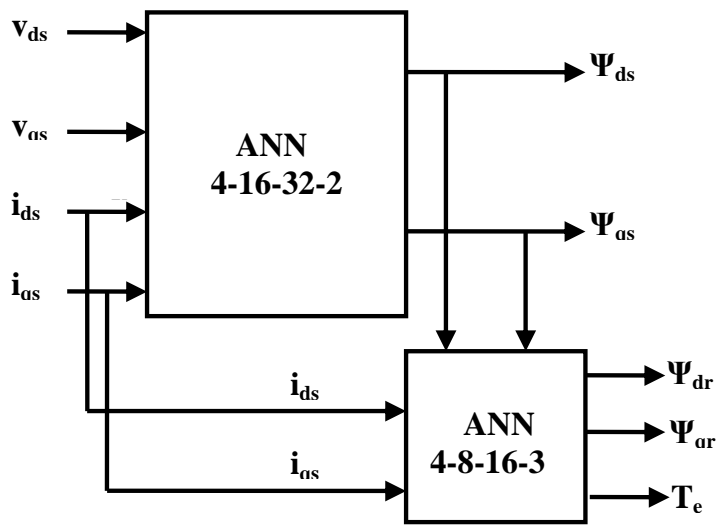

Fig. 2. block diagram of proposed ANN structure

programmable DSP kit (TMSLF 2407). The system data has been given in the Appendix. The preliminary measured parameters were vd, vq, id and iq; the DSP kit is capable of converting the three phase voltage and current data obtained from the practical drive system into corresponding $\mathrm{d}-\mathrm{q}$ components by using Park's Transformation [15]. These d-q data for voltages and currents are in turn used to estimate the other parameters with the help of the programming features of the kit with the help of (1) to (14). The values obtained thus for a known set of inputs (vd, vq, id and iq) give the known output values for the instantaneous magnitude and position of rotor flux and load torque, which serve as target values in training the Neural Network of Fig. 2. A comparative study was then conducted between the DSP estimator and the proposed ANN estimator.

\section{A. Estimation of the Instantaneous Magnitude and Position of Rotor Flux}

Fig. 3 shows, estimated value of stator d-axis flux at no-load torque up to 0.6 seconds and after that load torque varies $7 \mathrm{Nm}$. The machine starts from standstill and hence takes a time of $0.02 \mathrm{sec}$ to establish the stator flux linkage with high currents. The ANN based d-axis flux and DSP based d-axis flux reach peak value of $2.55 \mathrm{~Wb}$ at the same time of $0.02 \mathrm{sec}$. In the case of ANN based estimator, the peak value of flux is maintained constant throughout the operation, and its value is slightly higher as compared to DSP based peak flux of $2.50 \mathrm{~Wb}$.

Fig. 4 shows the stator q-axis flux on the same load conditions. ANN based estimation of stator q-axis flux and DSP based estimation of flux reach the peak value at $0.02 \mathrm{sec}$. Both the estimated values have close resemblance but ANN based peak flux is slightly higher than DSP based peak flux of $2.74 \mathrm{~Wb}$.

Rotor $\mathrm{d}$-axis and q-axis flux and position are estimated using above estimated $\mathrm{d}$-axis and $\mathrm{q}$-axis stator flux. Fig. 5 shows rotor d-axis flux as the load torque varies from no-load to $7 \mathrm{Nm}$ at 0.6 seconds and remains constant after this. The given plots show this transition time for the sake of clarity. The ANN based d-axis flux and DSP based d-axis flux reach peak value of $2.55 \mathrm{~Wb}$ at the same time of $0.05 \mathrm{sec}$. In the case of based estimator, the peak value of flux is maintained constant throughout the operation, and its value is slightly higher as compared to DSP based peak flux of $2.48 \mathrm{~Wb}$. Fig. 6 shows the rotor q-axis flux on the same load conditions. ANN based estimation of rotor q-axis flux reach the peak value $0.06 \mathrm{sec}$ while DSP based estimation of flux reach the peak value after $0.18 \mathrm{sec}$. Both the estimated values have close resemblance but ANN based peak flux $(2.5 \mathrm{~Wb})$ is slightly higher than DSP based peak flux of $2.48 \mathrm{~Wb}$.

After successful estimation of stator flux by the first ANN structure, the rotor flux magnitude is estimated. The target values for the known inputs were obtained using the machine dynamic equations (7) to (13). ANN based and DSP based estimation of rotor flux at different load conditions are shown in Figs. 7 to 9. In all the cases ANN based rotor flux reach the peak value after approximately $0.02 \mathrm{sec}$, whereas DSP based estimation of flux reach the peak value after $0.15 \mathrm{sec}$. This is due to the fact that the computation time involved in ANN is 
much less compared to traditional DSP estimation, as pointed in section III. However, there are ripples present in ANN based estimation technique. The ripple generated by the network is evident on flux, yet it is not so significant on the full scale. The ripple amplitude can be further attenuated with a low pass filter of small time constant. In all the cases, ANN based estimated flux reach the peak value at $0.02 \mathrm{sec}$, whereas DSP based estimation of flux reaches its peak value after $0.15 \mathrm{sec}$. Both the estimated values have close resemblance as clear from the results. Fig 10 shows the estimation of rotor position, which is seen as the angle of the estimated rotor flux.

\section{B. Estimation of the Load Torque}

The load torque estimation using ANN and DSP estimator is shown in Figs. 11 to13 for various load conditions. The torque response is almost instantaneous, with certain switching frequency ripples on it. The ripple on the estimation of flux is found to have no significant effect on torque or speed. It was also observed that the estimation with ANN stabilizes much faster than DSP technique. As ANN based estimated flux is slightly higher than DSP estimated flux values, it results in higher estimated value of torque for ANN based estimator. In case of overload as shown in Fig. 13 higher ripple was seen as compared to lightly loaded conditions due to coupling effect. At light load in all the cases DSP and ANN estimators give good resemblance in responses. The ANN based estimator shows faster response and demonstrates a harmonic-immune performance. Furthermore, ANN is known for its very good interpolation capability and the torque of $6-\mathrm{Nm}$ is in the higher side of the machine rating; if the results are in good match for this value, then it is expected to be true for any other load condition within the operating range.
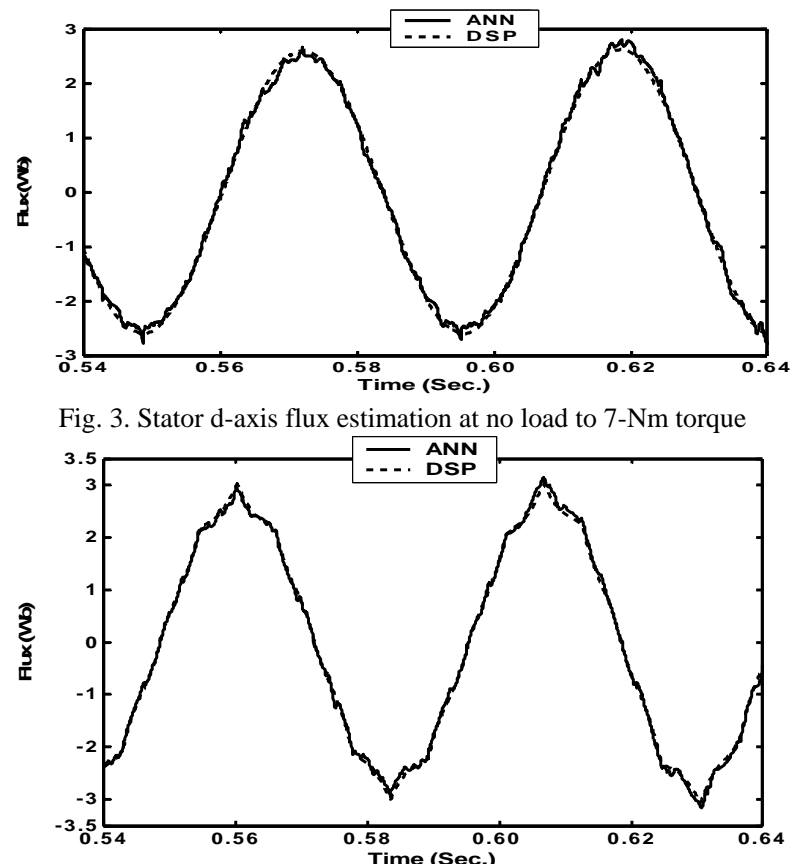

Fig. 4. Stator q-axis flux estimation at no-load to 7-Nm torque

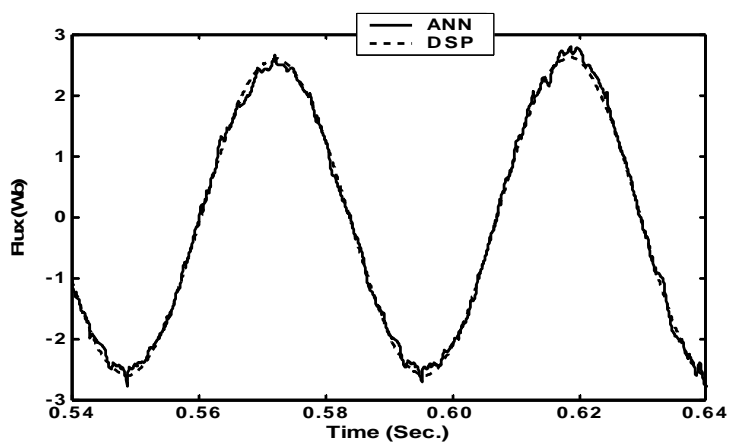

Fig. 5. Rotor d-axis flux estimation at no-load to 7-Nm torque

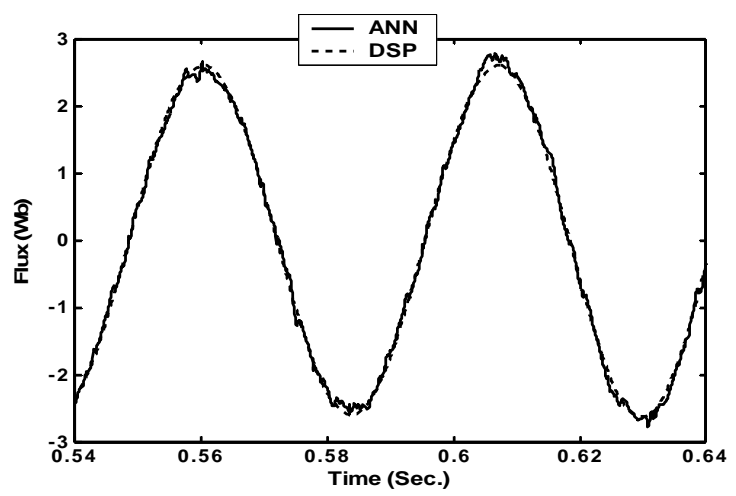

Fig. 6. Rotor q-axis flux estimation at no-load to 7-Nm torque

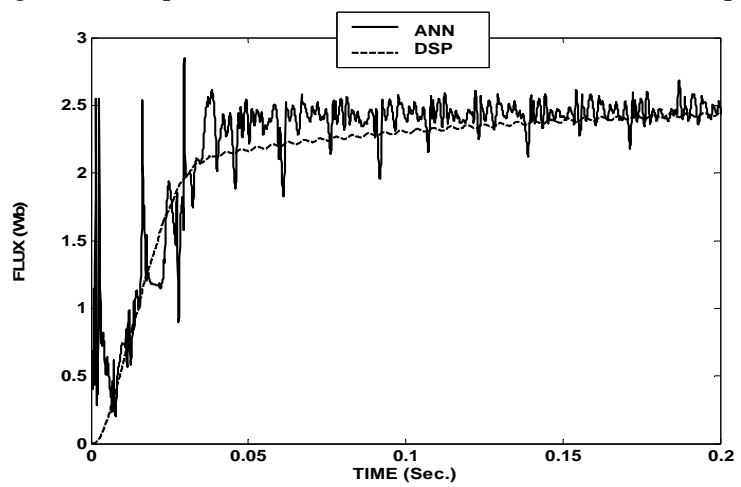

Fig. 7. Rotor flux magnitude estimation at 2-Nm and 5-Nm torque

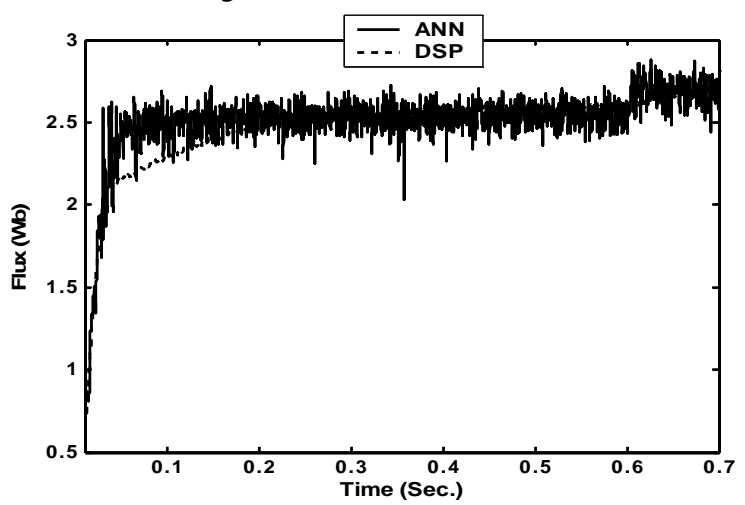

Fig. 8. Rotor flux magnitude estimation at 3-Nm and 6-Nm torque

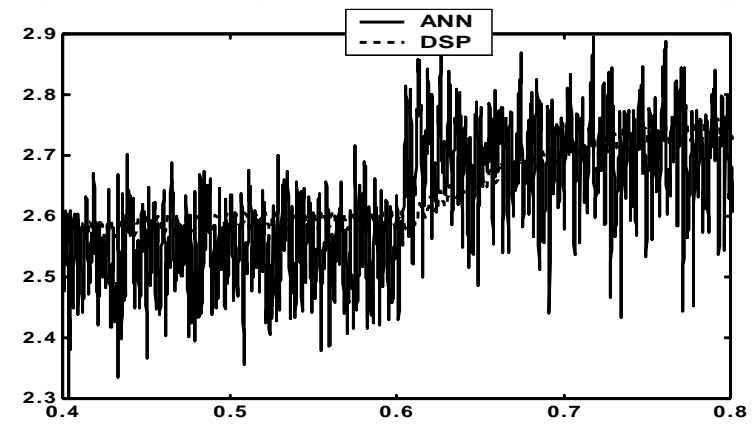

Fig. 9. Rotor flux magnitude estimation at no-load to 7-Nm torque 


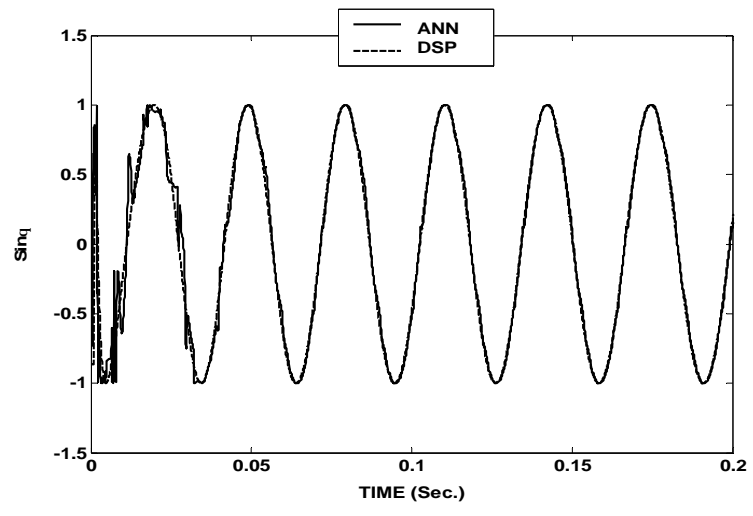

Fig. 10. Rotor position estimation

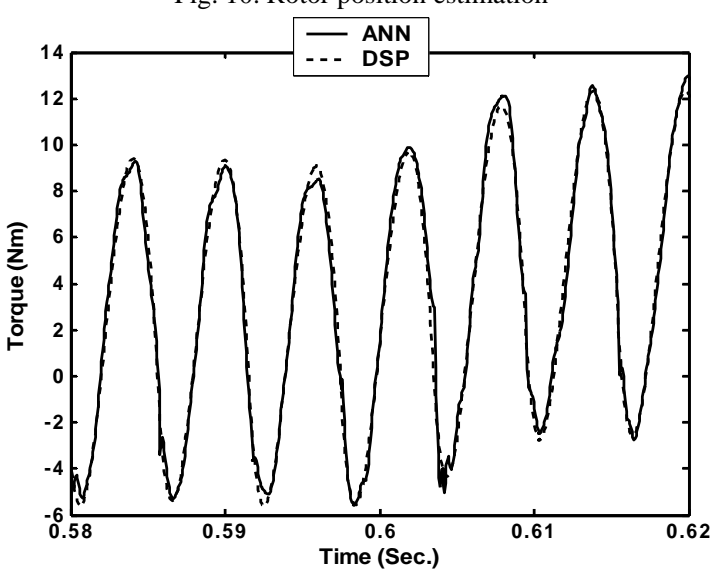

Fig. 11. Load torque estimation at 2-Nm and 5-Nm torque

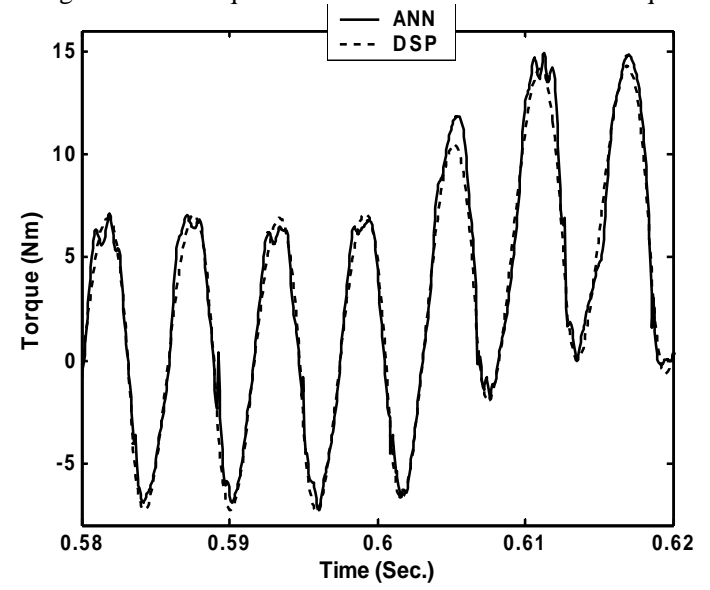

Fig. 12. Load torque estimation at 3-Nm and 6-Nm torque

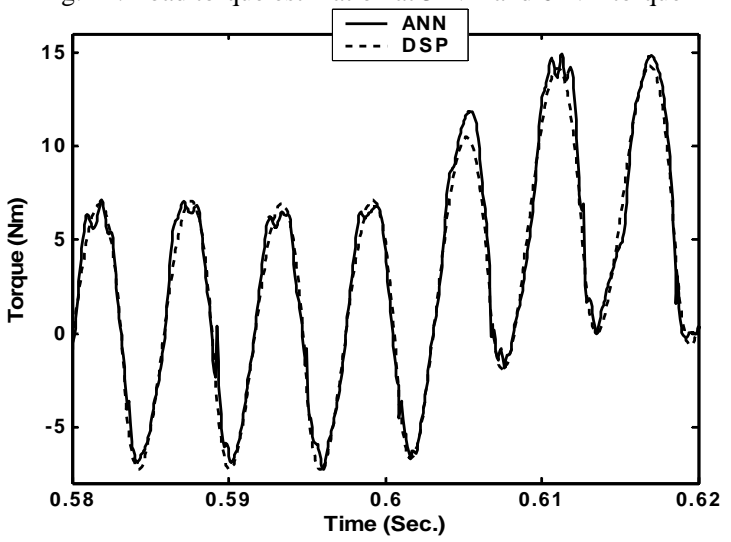

Fig. 13. Load torque estimation at no-load to 7-Nm torque

\section{CONCLUding REMARKS}

A vector-controlled induction motor drive has been studied in this work under dynamic load conditions. A feedforward-neural-network is used for estimation of the instantaneous magnitude and position of rotor flux and load torque. The proposed estimator can also estimate other motor parameters such as motor speed. Load torque values are changed from no-load to over load condition and intermediate load conditions were also considered. In all the conditions speed reference is set to $120 \mathrm{rad} / \mathrm{sec}$. The results obtained successfully demonstrate the application of ANN in the estimation of the instantaneous magnitude and position of rotor flux and load torque for a vector controlled induction motor drive system. A four-layer feedforward neural network of the structure 4-16-32-2 neurons in the respective layers has been trained for estimation of stator d-axis and q- axis flux. Similarly, the second feed-forward neural network structure of 4-8-16-3 neurons has been trained for estimation of the instantaneous magnitude and position of rotor flux and load torque. This two stage structure is a novel contribution of this work and is found to be very efficient in training and gives a better accuracy as compared to a one stage ANN structure. The performance of the proposed ANN estimator is found to be excellent in comparison to DSP based estimator, particularly in terms of processing time, which leads to a stable response much faster under changing load conditions.

The conventional numerical methods for parameter estimation are based on equations solving. It is possible to calculate the flux or torque, from transient to steady state using the machine differential equations, which require electrical and mechanical parameters of the machine, such as resistances and inductances. Non-availability of the parameters like resistances and inductances under dynamic load conditions may lead to inaccurate results with the traditional approach. A programmable DSP requires high computational effort for application. In contrast, the ANN based estimator shows faster response and also demonstrates a harmonic-immune performance.

\section{APPENDIX}

Three phase squirrel cage induction motor specifications

\begin{tabular}{|l|l|l|l|}
\hline S.N & Parameter & Symbol & Value \\
\hline 1 & Power Supply & $3 \Phi$ & -- \\
\hline 2 & & $\mathrm{f}$ & $50 \mathrm{~Hz}$ \\
\hline 3 & Supply Frequency & & \\
\hline 4 & Voltage & $\mathrm{V}$ & $415 \mathrm{~V}$ \\
\hline 5 & Connection Type & $\mathrm{Y}$ & -- \\
\hline 6 & Stator Resistance & $\mathrm{R}_{\mathrm{s}}$ & $6.03 \Omega$ \\
\hline 7 & Stator Inductance & $\mathrm{L}_{\mathrm{s}}$ & $29.9 \mathrm{mH}$ \\
\hline 8 & Rotor Resistance & $\mathrm{R}_{\mathrm{r}}$ & $6.085 \Omega$ \\
\hline 9 & Rotor Inductance & $\mathrm{L}_{\mathrm{r}}$ & $29.9 \mathrm{mH}$ \\
\hline 10 & $\begin{array}{l}\text { Magnetizing } \\
\text { Inductance }\end{array}$ & $\mathrm{L}_{\mathrm{m}}$ & $489.3 \mathrm{mH}$ \\
\hline 11 & Moment of Inertia & $\mathrm{J}$ & $0.011787 \mathrm{kgm} 2$ \\
\hline 12 & Damping & $\mathrm{B}$ & $0.0027 \mathrm{Nm} / \mathrm{rad} / \mathrm{sec}$ \\
\hline 13 & Number of Poles & $\mathrm{p}$ & 4 \\
\hline
\end{tabular}

\section{REFERENCES}

[1] B. K. Bose, Modern Power Electronics and AC Drives. 5th ed. Singapore: Pearson Education, 2005. 
[2] P. C. Sen, Principles of Electric Machines and Power Electronics. 3rd ed. New York: Wiley, 1988.

[3] W. Leonhard, Control of Electric Drives. 3rd ed., New York: Springer, 2001.

[4] R. Krishnan, Electric Motor Drives: Modeling, Analysis and Control, 1st ed., Singapore: Pearson Education, 2001.

[5] Jennifer Stephan, Marc Bodson, and John Chiasson, "Real-time estimation of the parameters and fluxes of induction motors", IEEE Trans. on Industry Applications, vol. 30, No. 3, May/Jun 94, pp.746759.

[6] P. Alexei, and Z. Alex, "Direct torque and flux regulation in sensorless control of an induction motor", in Proc. of the American Control Conf, Arlington, VA, Jun. 25-27, 2001, pp. 137-142.

[7] Yen-Shin Lai, "A new approach to direct torque control of induction motor drives for constant inverter switching frequency and torque ripple reduction ", IEEE Trans. on Industry Applications, vol. 16, No. 3, Sept 2001, pp. 220-227.

[8] P. Ponce and J. Santos "A novel sensorless direct torque controlled induction motor drive", in Proc. of the IEEE IEMDC conf. Madison WI pp 971-975, 2003.

[9] P. Vas, A. F. Stronach and M. Neuroth, "DSP-based speed-sensorless vector controlled induction motor drives using AI based speed estimator and two current sensors", in Proc. of the Power Electronics and Variable Speed Drives, (Conference Publication No. 4560 IEE 1998), 21-23 September 1998, pp. 442-446.

[10] O. K. Teresa and T. K. Czeslaw, "Neural network application for flux and speed estimation in the sensorless induction motor drive", in Proc. of ISIE'97, Guimaraes, Portugal, (IEEE Cat. No. 97TH8280), 1997, pp 1253-1258.

[11] K. K.P. Allan, P. N. Edwin, and A. Farhad, "A flux estimator for field oriented control of induction motor using artificial neural network", IEEE Trans. on Industry Applications, vol. 1, 1994, pp. 585-592.

[12] P. P. Cruz and Jaime J. Rodriguez Rivas, "A small neural network structure application in speed estimation of an induction motor using direct torque control", IEEE Trans. on Industry Applications, 2001, pp. 823-827.

[13] M. N. Cirstea, A. Dinu, J.G. Khor, and M. McCormick, Neural and Fuzzy Logic Control of Drives and Power Systems. 1st ed., Oxford Newnes Pub. (ISBN 07506 55585), 2002.

[14] A. Ba-Razzouk, A.Cheriti, and G. Olivier, "Artificial neural networks rotor time constant adaption in indirect field oriented control drives", in Proc. of the IEEE 1996 (Conference Publication No. 0-7803-3500-7/96), pp. 701-707.

[15] D. D. Neema and A. S. Zadgaonkar, "Matlab simulation of three phase to two phase transformation and vice-versa", in Proc. of the National Conference on Innovation in Engineering and Technology - INVENT 2007, Gondia (M.S.), India, on $14^{\text {th }}-15^{\text {th }}$ March, 2007.

[16] P. Jansen and R.D. Lorenz, "A physically insightful approach to the design and accuracy assessment of flux observes for field oriented induction machine drives", IEEE IAS Annual Meet. Conf. Rec., 1995, pp. 570-577.

[17] M.G. Simoes and B.K. Bose, "Neural network based estimation of feedback signals for a vector controlled induction motor drive", IEEE Trans. on Industry Applications, vol. 31, No. 3, May/Jun 95, pp. 620-629.

[18] B.K. Bose, "Expert system, fuzzy logic, and neural network application in power electronics and motion control", Proc. of the IEEE vol. 82, No. 8, Aug. 94, pp. 1303-1323.
[19] Martin T. Hagan, Neural Network Design. $5^{\text {th }}$ ed., PWS Publications 1996.

[20] R. Patel and K.V. Pagalthivarthi, "Artificial Neural Network Based Turbine Fast Valving for Enhancement of Power System Transient Stability", Journal of Electrical Engineering, IEE Slovak Centre, vol. 57, No. 1-2, 2006, pp. 1-9.

[21] Simon Haykin, Neural networks: A Comprehensive Foundation. $2^{\text {nd }}$ ed., Singapore: Pearson Education, 2004.

[22] Ramnarayan Patel, T.S. Bhatti and D.P. Kothari, "MATLAB/ Simulink based transient stability analysis of a multi-machine power system", International Journal of Electrical Engineering Education (IJEEE), vol. 39, No. 4, pp. 320-336, Oct. 2002.

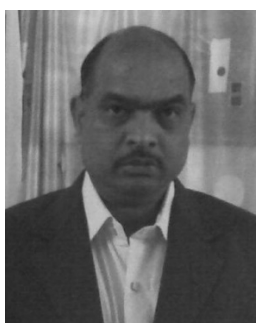

D.D. Neema did his B.E. in Electrical Engineering in from SGSITS Indore (M.P.), and M.E.in control systems from Jodhpur (Raj.) India. He is a Reader in Electrical Engineering Department at RCET Bhilai (C.G.). He has a rich teaching \& industrial experience of 23 years in reputed institutions. $\mathrm{He}$ is presently enrolled as a research scholar in CSVT University Bhiali (C.G.) India. His fields of interest are application of Artificial Intelligence in drives and Vector control of drives.

Dr. A.S. Thoke did his B.E., M. Tech. \& PhD. all in Electrical Engineering.

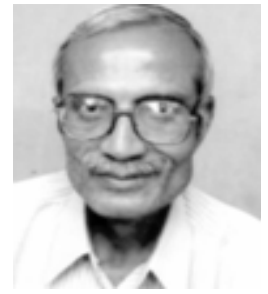
$\mathrm{He}$ is a Professor in Electrical Engineering Department at National Institute of Technology, Raipur (C.G.), India. Dr. Thoke has a teaching \& research experience of 32 years. His fields of interest are application of Artificial Intelligence to Power system with particular interest in protection. Dr. Thoke is Member of IEEE (03).

Dr. R.N. Patel did his B.E. in Electrical Engineering in year 1997. He acquired his M. Tech. and Ph. D. (Power Systems) degrees from IIT Delhi

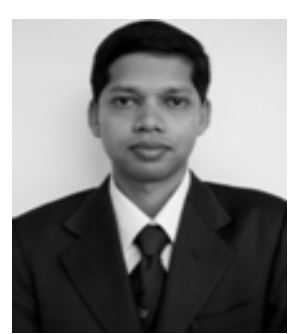
in years 1998 and 2002 respectively. He has worked as a faculty of Electrical Engineering in IIT Roorkee during year 2003-2006. Presently he is working with the Electrical Engineering department at SSCET, Bhilai, India. His main fields of interest are: Power System dynamics and Stability, Modelling of Power Systems and AI applications to Power Systems. Dr. Patel has more than 50 publications in various International Journals and Conferences. Dr. Patel is Member of IEEE (09). 